\title{
Performance of Powersystem to Enhance Power Quality using Fuzzy Logic Controller Based DVR
}

\author{
Nakka.Mahesh Babu, Md.Aijaz
}

\begin{abstract}
This paper accord the Power Quality interpretation to make apparent for electricity consumers been made better power quality with application of DVR.Despite of advantages of $D V R$, it focuses full extent of the relatedness surrounded by loads, various power networks. DVR is most accepted power device which could be used for better solution for the disturbances of voltages in distribution systems for sensitive loads. For efficiency considerations, the DVR mostly hinge on an act of presenting the control modus, and can be harnessed to switching the inverters. Reliability of hysteresis voltage control with ease in operation under variable switching frequency can be trustworthy for a DVR can introduced and the proposed methods achieves good compensation of voltages under disturbances and can be seen by the simulation by using fuzzy logic controller.
\end{abstract}

Keywords:DVR, FLC , Hysteresis voltage controller, PI controller, phase modulation

A DVR is proposed to compensate voltage levels. Important design guide lines viz. control delay and filter cutoff frequency are also proposed for the controller of a DVR[1].Controlling of harmonic voltage distortions to acceptable level is a primary role of the filter. DVR performance can be affected by the filter design considerations. DVR inverter rating can be influenced by the establishment of the filter parameter selection. These considerations are very important for a systematic design [3].In circulation DC tie-up capacitor perhaps utilized for voltage smoothening and not for energy storage. Three phase recompense voltages are superimposed by the zero sequence components as per controlling mechanism. Gating signals to the switches of DVR described by inner loop.DVR inverter output based on harmonic spectrum can be designed for filter capacitor for the guaranty of DVR load voltage THD with in prescribed limit with Filter capacitor effect analyzed. fix up of the filter plan, at workability side and burden side, the DVR not only recompense the voltage troubles likewise ensures the power status of the supply which is described in a novel methodology for the construction of DVR.A DVR based on voltage space vector PWM algorithm. A battery charging controlling technique also applied for DVR.A four leg VSC based DVR closed loop controlling, implementing controller functions from digital controller based on Digital Signal Processor (DSP).

Revised Manuscript Received on February 05, 2020.

* Correspondence Author

Nakka. Mahesh babu*, Assistant professor, Department of Electrical and Electronics Engineering, Kodad Institute of Technology\&Sciences women,Kodad..(Email;mahesh5585204@gmail.com).

Dr.MD.AIJAZ, Assistant Professor, Department of Electrical and Electronics

Kodad,suryapet,district,(Email:aijaz.vsce@gmail.com) Engineering

(C) The Authors. Published by Blue Eyes Intelligence Engineering and Sciences Publication (BEIESP). This is an open access article under the CC BY-NC-ND license (http://creativecommons.org/licenses/by-nc-nd/4.0/)

\section{I.INTRODUCTION}

A program was developed to resolve three phase variables in to sequence components. For the controlling of DVR, two techniques from SVM . They compared between conventional multi level SVM steemed with number of levels and the proposed SVM. The proposed SVM helps in reduction of inverter switching losses and harmonic performance. The dynamic voltage restorer having ability to store additional energy. It has been observed that the sharp variations can be observed in a system. With random improvements in technology, the modern industries utilizing devices of power electronics based devices, PLC (programmable logic controllers) and availability of renewable energy sources. under fault conditions and for improvement obstacle of of power like voltage slumps, bulges and variations of harmonics electronic devices has a tendency to act responsibly and fast acting in operation also they are accurate in getting results. Short of voltages also known as voltage sags are the sudden drops of rms voltages are observed as most undesirable effect to the industrial components DVR's are the class of widely used power devices for providing compatible improvement in power of the distribution systems.DVR uses voltage boost concepts with the use of solid state switches for compensation of raise or fall of rms voltages. The DVR is applicable mostly for loads where sensitive variation is possible that may Cause considerable damage to the systems voltage and equipments. Among the issues 0bstacles of power like slumps, bulges, harmonics etc..., voltage slumps are the severe disturbances .In distribution systems DVR is the most promising device in power electronic devices for its efficient operation.DVR is placed at the location where critical load feeder and utility at common coupling point.

Fuzzy logic controller with PI controller introduced for the modeling of DVR to enhance the systems performance. The above model's main objective is to improve quality of power during different types of faults like 3-phase fault, single L-G fault and double Line fault points.

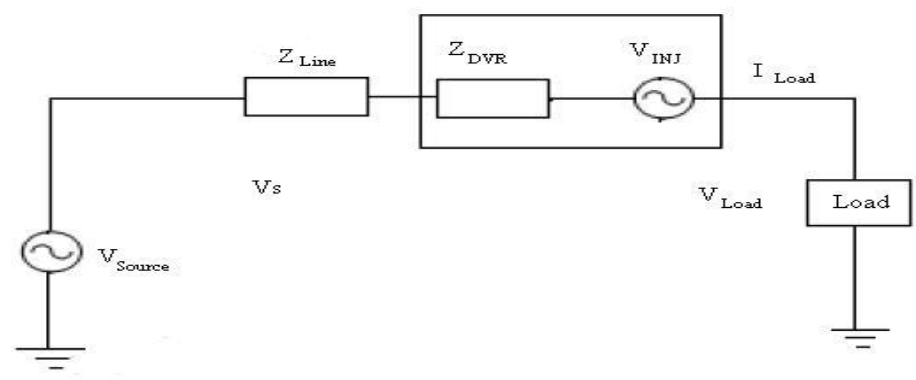

Figure 3. CONFIGURATION OF DVR.

From the circuit shown in fig.3. The series inoculate voltage of the DVR can be written as




$\mathrm{V}_{\mathrm{Dvr}}=\mathrm{V}_{\mathrm{L}}+\mathrm{Z}_{\mathrm{th}}-\mathrm{V}_{\mathrm{Th}}$

(1)

Where

\begin{tabular}{|l|l|}
\hline$V_{L}$ & Load voltage \\
\hline$Z_{t h}$ & Thevinin impedance \\
\hline$I_{L}$ & Load current \\
\hline$V_{T H}$ & Thevinin voltage \\
\hline
\end{tabular}

Load current is given by

$\mathrm{I}_{\mathrm{L}}=\quad\left[\mathrm{P}_{\mathrm{L}}+\mathrm{JQ}_{\mathrm{L}}\right]$

(2)

$\mathrm{V}_{\mathrm{L}}$

When $\mathrm{V}_{\mathrm{L}}$ is reference equation and can be rewritten as,

$\mathrm{V}_{\mathrm{dvr}}\left\llcorner\alpha=\mathrm{V}_{\mathrm{L}}\left\llcorner 0+\mathrm{Z}_{\text {th }}\left\llcorner(\beta-\theta)-\mathrm{V}_{\text {th }}\llcorner\delta\right.\right.\right.$

(3)

The injected DVR complex power can be written as,

$\mathrm{S}_{\mathrm{Dvr}}=\mathrm{V}_{\mathrm{Dvr}} \mathrm{I}_{\mathrm{L}}{ }^{*}$

(4)

\section{II.CONTROL STRATEGIES WITH PI CONTROLLER}

The do ones utmost of the predominance tack is to preserve invariable voltage immensity on the knife edge where a quick to detect load is bridged, beneath the system troubles. The controlling of system only assess the $\mathrm{V}_{\text {rms }}$ at the work station of load, and not required any reactive power requirements. The changes of (VSC) voltage source converter outlook root on a SPWM execution, which put forward to intelligibility and accurate reaction. Subsequently conventional power is a equivalently low-potential approach, PWM method, offers a more pliable substitution than the FFS methods. The PI controller with set voltage and terminal voltage shown in fig. The importance of the PI controller is to maintain the switching movement to the required value.



Figure 4. PI Controller

The hysteresis voltage controller invariably used to appropriate signals by comparing the set voltage and reference voltage of DVR. When the dissimilarity between the instant and inverter voltage extend to the higher/ under limit, the voltage is weighs to narrows or enlarge as shown in Figure 5.

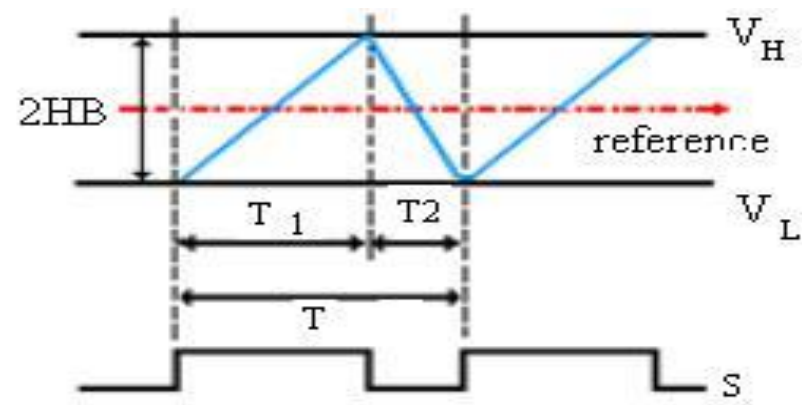

Figure 5.Hysterisis Band Voltage Control

\section{III.FUZZY LOGIC CONTROLLER}

FLC provides two real inputs which are named as error and error rate and the actuating signals developed at the output.

$\mathrm{E}_{\mathrm{rrA}}=\mathrm{V}_{\mathrm{pllA}}-\mathrm{V}_{\mathrm{sA}}$

$\Delta \operatorname{Err} A=\operatorname{ErrA}(\mathrm{n})-\operatorname{ErrA}(\mathrm{n}-1)$

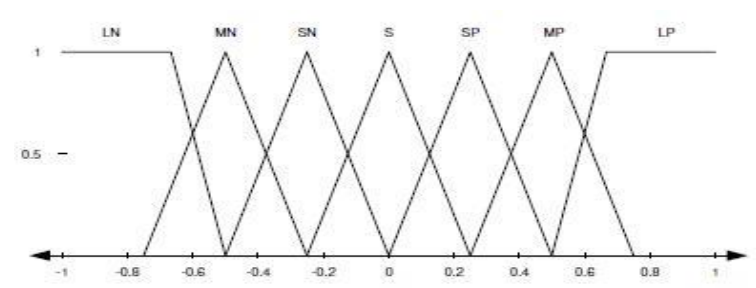

Figure 6.Input variable "Error" membership function

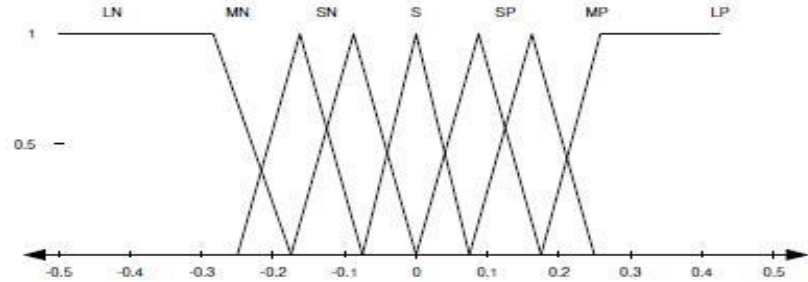

Figure 7. "Error rate"membership function


Figure 8. Output membership.

The insert space is portray to the membership ranging values from 0 and 1 which are wavy that show how every point of input varies between 0 and 1.for the other phases these membership functions are identical.

Fig.6 and fig.7 notifies the inputs with membership functions. Similarly fig. 8 shows membership function for output variable. 
Table 1.fuzzy logic control rule view

\begin{tabular}{|c|c|c|c|c|c|c|c|c|}
\hline \multicolumn{2}{|c|}{} & \multicolumn{7}{|c|}{ Error Rate } \\
\cline { 2 - 9 } \multicolumn{2}{c|}{} & LP & MP & SP & S & SN & MN & LN \\
\hline \multirow{4}{*}{} & LP & PB & PB & PB & PM & PM & PS & Z \\
\cline { 2 - 9 } & MP & PB & PB & PM & PM & PS & Z & NS \\
\cline { 2 - 9 } & SP & PB & PM & PM & PS & Z & NS & NM \\
\cline { 2 - 9 } & S & PM & PM & PS & Z & NS & NM & NM \\
\cline { 2 - 9 } & SN & PM & PS & Z & NS & NM & NM & NB \\
\cline { 2 - 9 } & MN & PS & Z & NS & NM & NM & NB & NB \\
\cline { 2 - 9 } & LN & Z & NS & NM & NM & NB & NB & NB \\
\hline
\end{tabular}

These 49 rules will represents the controlling action and the operating condition can be expressed by each rule. The person's experience and system know behavior helps to define the rules. All rules are evaluated in parallel and the order of the rules is not important. The rule view for FLC is shown in Table1.The outputs of FLC process are the control signals that are used in generation of PWM inverter converting signals by comparing a carrier signal. The generation of converting signals for single phase of the system, where the configuration will be the same for other phases.

\section{IV.DVR WITH PI AND FLC SIMULATION RESULTS}

Main system simulation model without DVR has been created in Mat lab, Simulink shown in fig.9



Figure 9.Main Systems without DVR

Fig.10 and fig.11 shows DVR with PI \&FLC. Alike system is composed by a generation system of $13 \mathrm{kv} 50 \mathrm{HZ}$, supplying two transmission lines through a $\mathrm{Y} / \Delta / \Delta 3$-winding transformer coupled with 13/115/1 lines feeding two distribution networks through $\Delta / \mathrm{Y}$ coupled two transformers of $15 / 11 \mathrm{kV}$.

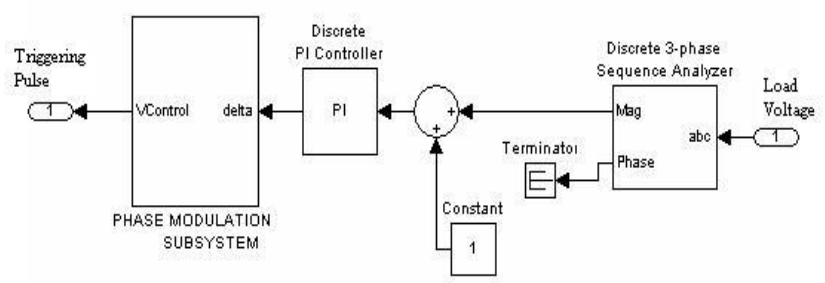

Figure 10.PI Controller subsystems

The following test system with no DVR during faults like 3ph fault, L-G fault and double line fault is analyzed.
Observed load voltage problems like sag, swell and interruption. Then to overcome these problems DVR is connected for the test system. PI Controller with parameters $\mathrm{KP}=0.5, \mathrm{Ki}=50$ \& sample time $50 \mu$ sec and FLC for the enhancement of the performance and THD improvement is observed.

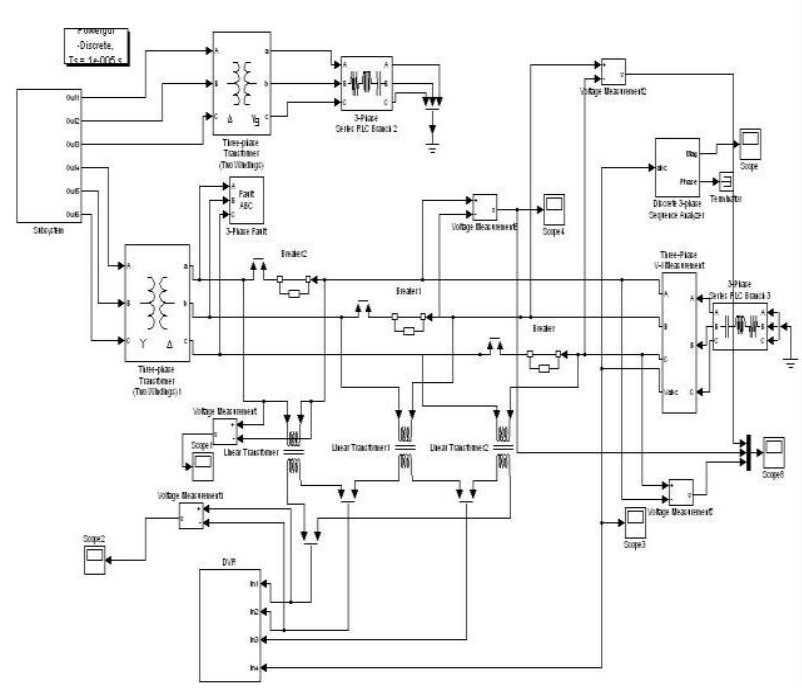

Figure 11. DVR with Fuzzy Logic Controller

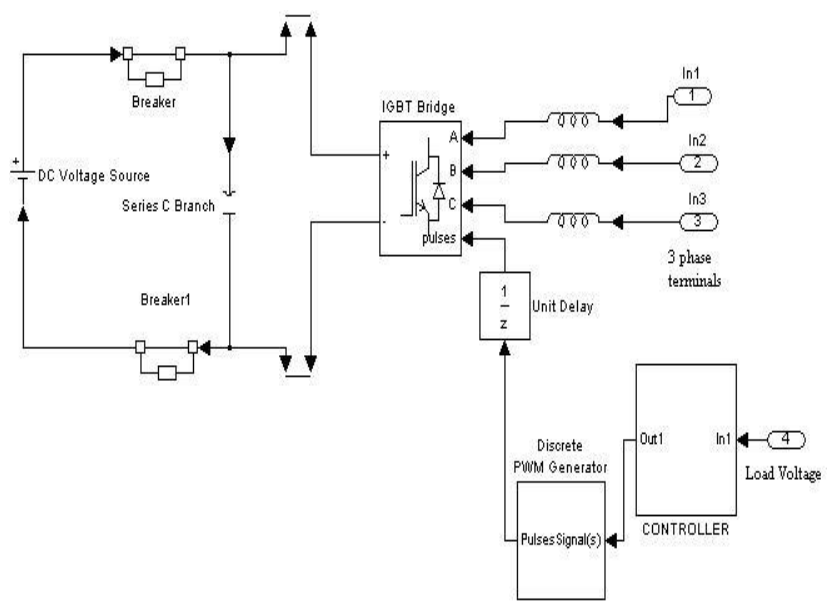

Figure 12.DVR subsystem

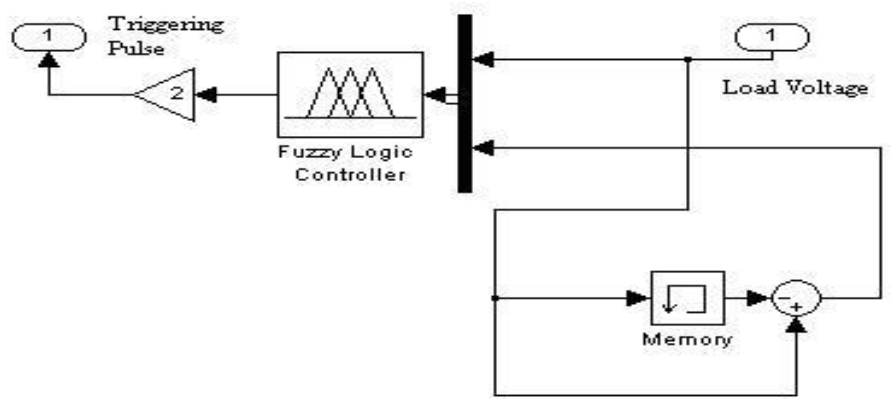

Figure 13.Fuzzy Logic Controller subsystems 


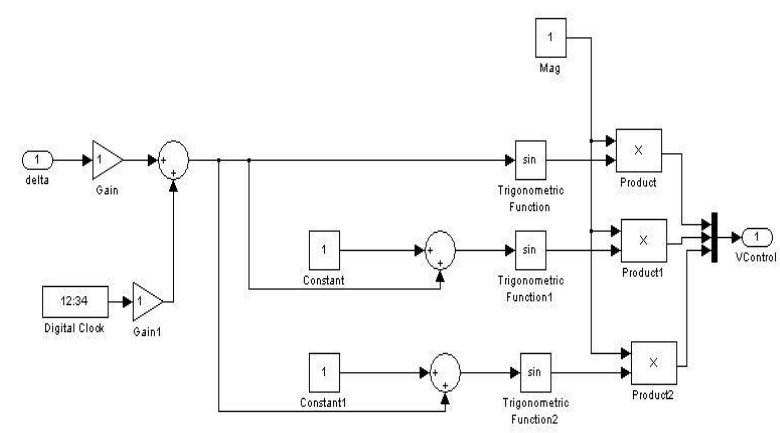

\section{V.SIMULATION RESULTS FOR SAG VOLTAGE DURING SINGLE L-G FAULT}

The test system fig.V.a shows RMS voltage without DVR.In fig.V.b, DVR with PI Controller \& DVR with FLC are in operation. The simulation period of total $1400 \mathrm{~ms}$.

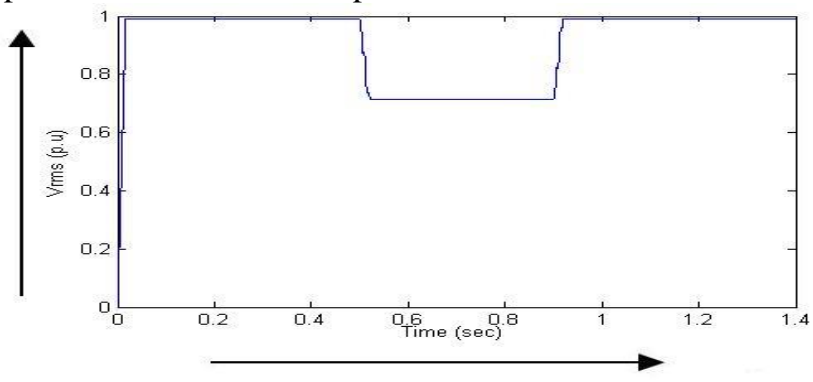

Figure (V. a)Voltage VRMS of load without DVR

The RMS voltage is 98\%, shown in Figure V. b.

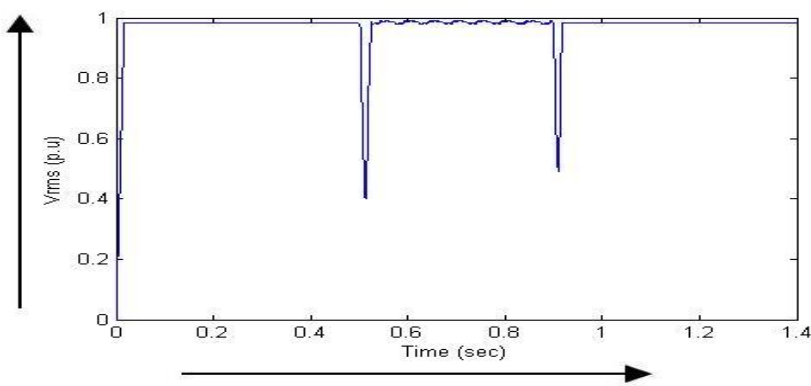

Figure (V .b) VRMS at the load with 6.5KV Energy Storage

The DVR response is smooth, stable and rapid to mitigate sag under single L-G fault. Figure V.b, Figure V.c, Figure V. d. and Figure V.e. Shows DC energy storage of 6.5KV, $6 \mathrm{KV}, 4 \mathrm{KV}$ and $8 \mathrm{KV}$ respectively.

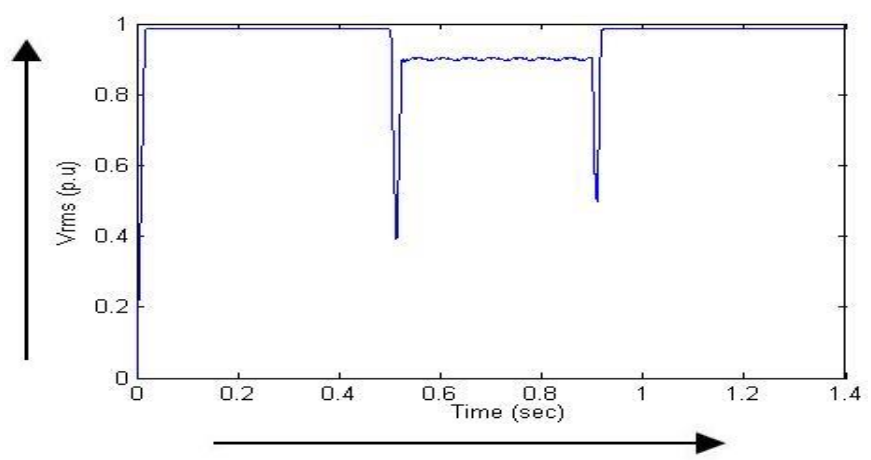

Figure (V. c) VRMs of load with 6KV Energy Storage

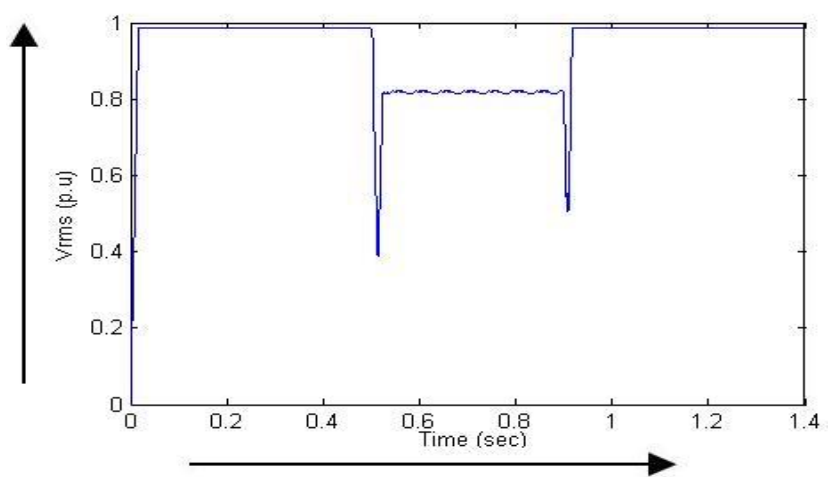

Figure (V. d) VRMS of load with 4KV Energy Storage

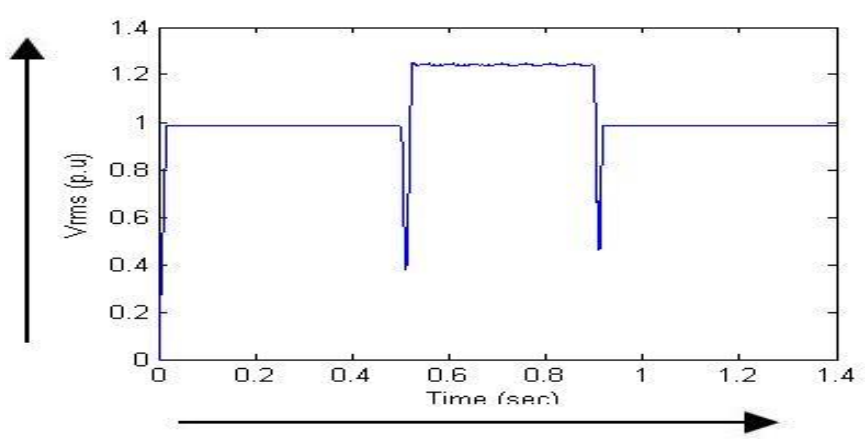

Figure (V. e) VRMS of load with 8KV Energy Storage

\section{VI.SIMULATION RESULT OF SAG VOLTAGE DURING}

\section{L-L FAULT}

The test system in fig.a shows RMS voltage without DVR

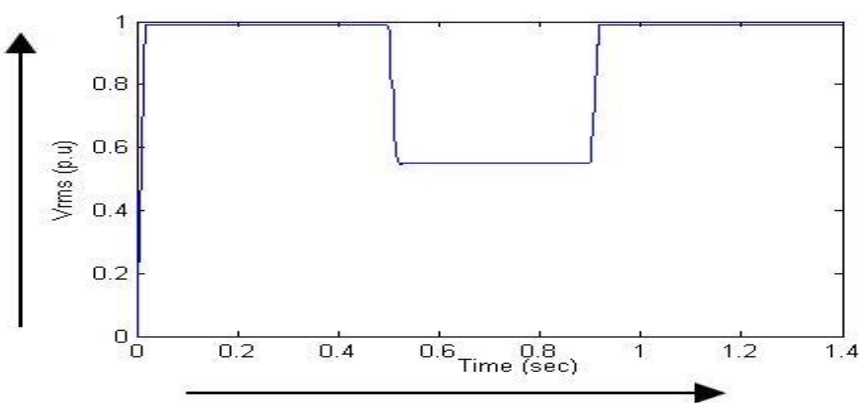

Figure VI.(a)V VMS of load without DVR

The RMS voltage is 98\%, as shown in Figure VI. b.

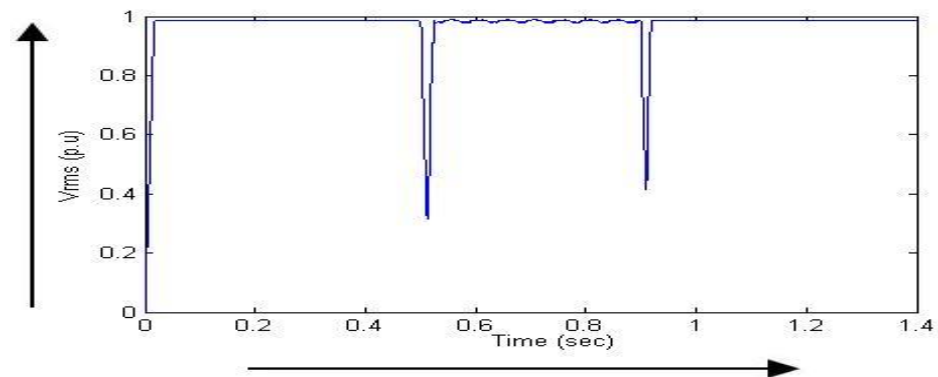

Figure VI. (b)VRMS of load with DVR Energy Storage of $6.68 \mathrm{KV}$

Published By:

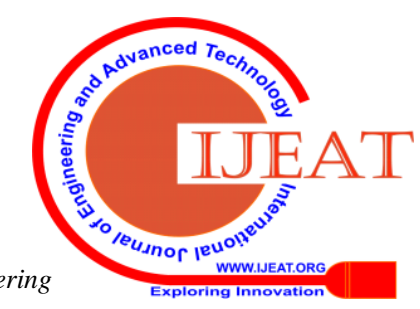


Figure VI. b, Figure VI. c, Figure VI. d and Figure VI. e, shows the potentiality of DVR depending upon capacity of $6.68 \mathrm{KV}, 6.2 \mathrm{KV}, 5.6 \mathrm{KV}$ and $8 \mathrm{KV}$ respectively.



Figure VI. (c) VRMs of load with 6.2KV Energy Storage

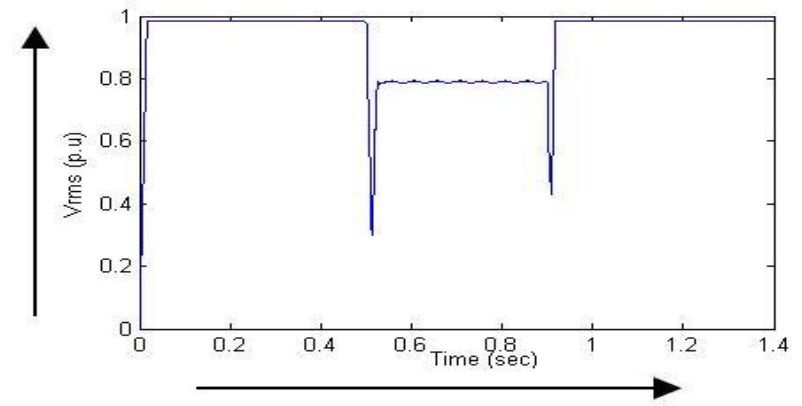

Figure VI. (d). VRMs of load with 5.6KV Energy Storage

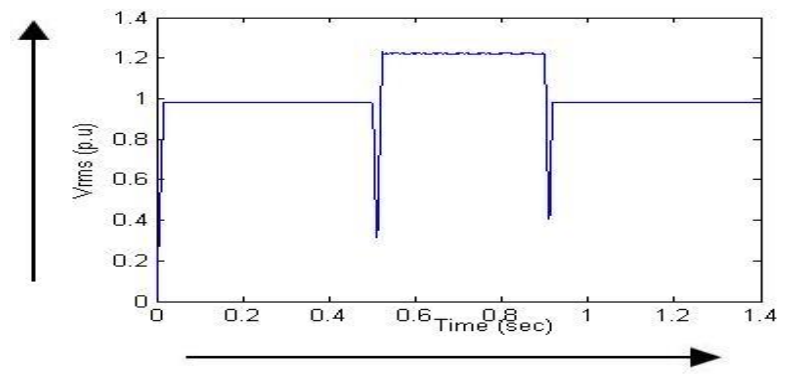

Fig VI. (e)Voltage VRMs of load with 8KV Energy Storage

\section{VII.VOLTAGE INTERRUPTION DURING THREE- PHASE FAULT SIMULATION RESULTS}

The test system in fig.VII.a. shows RMS voltage without DVR.



Figure VII. (a) VRMS at the load without DVR

The RMS voltage is $98 \%$, as shown in Figure VII.b.

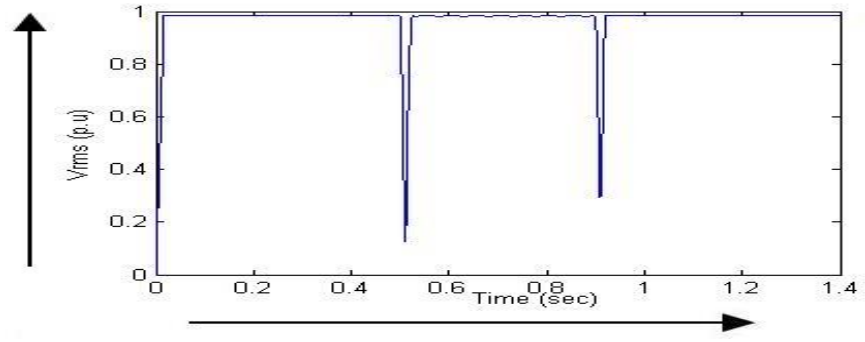

Figure VII. (b)VRMS of load with DVR Energy Storage of $4.9 \mathrm{KV}$

Figure VII. b. and Figure VII. c. are the compensating capability of DVR rely on the ability of the DC Energy Storage.

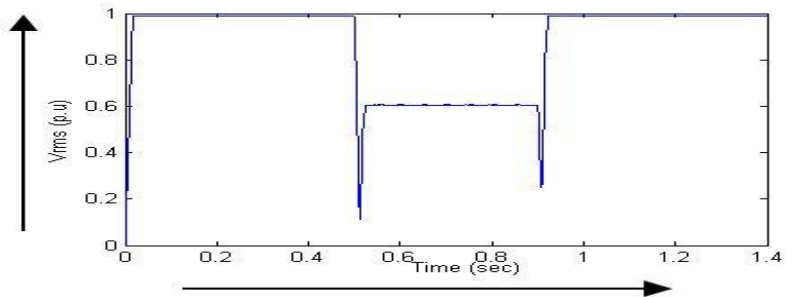

Figure VII.(c) VRMs of load with 3KV Energy Storage

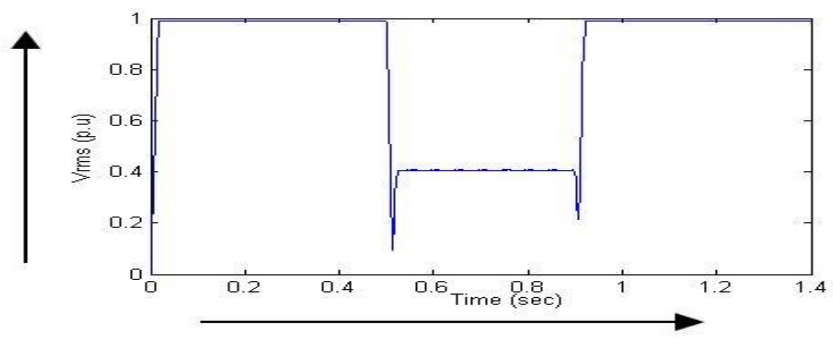

Figure VII. (d) VRMs of load with 2KV Energy Storage Figure VII.e. shows that the storage energy is more than the required it will give bulge at the load.

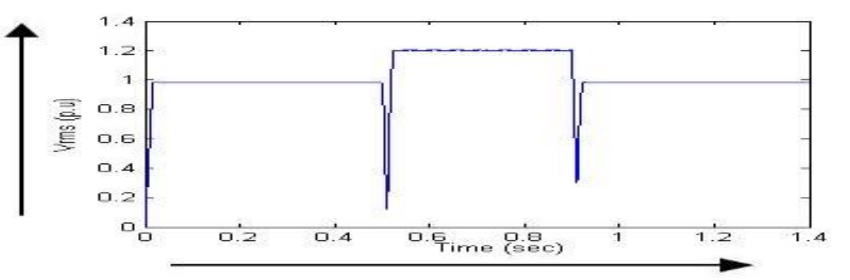

Figure VII.(e)Voltage VRMs of load with 7KV Energy Storage

\section{VIII.SIMULATION RESULT OF VOLTAGE SWELL}

The test system in Figure. VIII .a.shows RMS voltage without DVR.

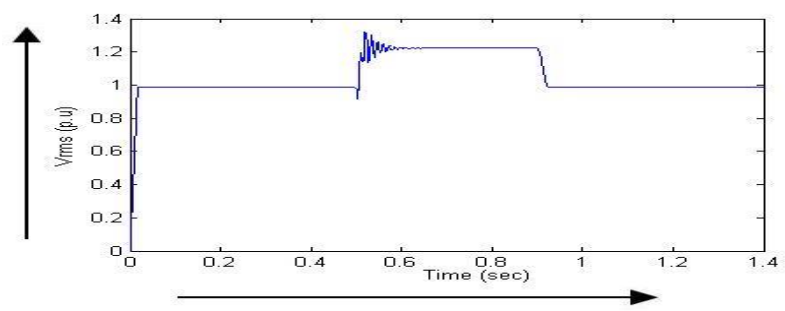

Figure VIII.(a)VRMs of load without DVR

The test system fig.VIII.b, is carried out using the same outlined as above but with DVR in operation. 
The total simulation time is $1400 \mathrm{~ms}$. The voltage swell is almost mitigated completely and the RMS voltage at the quick detecting load is continued normal, as shown in Figure.VIII.b.

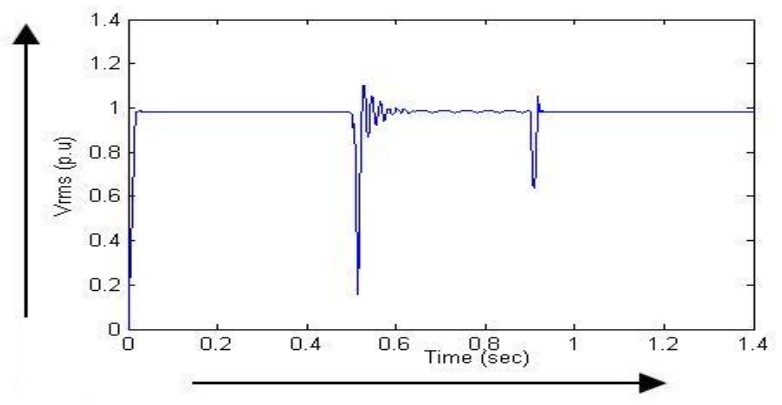

Figure VIII.(b)VRMs at the load with DVR Energy Storage of $6.8 \mathrm{KV}$

\section{IX.CONCLUSION}

DVR is come up with series connected rigidly in order to inject \& regulate the voltages into the system \& the load side. DVR also having additional capability Other than voltage sags and swells compensation, it can also having other attributes, those are line voltage harmonics compensation, reduction of transients in voltage and fault current limitations and then analyze the dynamic and steadystate performance of DVR. The results of voltage and current waveforms of DVR using PI Controller and Fuzzy Logic Controller with voltage sag during three phase fault sag voltage during single L-G fault, sag voltage during double line fault, voltage interruption during 3 phase fault and voltage swell points are analyzed. DVR with Fuzzy Logic Controller performs better among DVR with PI and FLC.

\section{REFERENCES}

1. Hyosung kim,seung- ki sul"compensation voltage control in dynamic voltage restorers by using feed forward, state feedback scheme"IEEE transactions on power electronics,volume-20,issue-5,September-2005

2. S. S. Choi, B. H. Li, and D. M. Vilathgamuwa, "Design and analysis of the Inverter-Side Filter Used in the Dynamic Voltage Restorer'IEEE Transactions on power delivery, vol. 17, no. 3, july 2002 .

3. N.H. Woodley, L. Morgan and A. Sundaram, ,"Experience With an Inverter-Based Dynamic Voltage Restore IEEE Trans. Power Delivery, 4.Changjiang Zhan, Atputharajah Arulampalam and Nicholas Jenkins, "Four-Wire Dynamic Voltage Restorer Based on a Three-Dimensional Voltage Space Vector PWM Algorithm",IEEE Transactions on power electronics, vol. 18, no. 4, july 2003.

4. B.H.Li, S.S. Choi and D.M. Vilathgamuwa, "Transformerless dynamic voltage restorer",-Gen.Trunsm.Dktrib., Vol.149, No. 3, May 2002.

5. S.R. Naidu D.A. 6. Fernandez, "Dynamic v a four-leg voltage source converter” IET 2009, Vol. 3, Iss. 5, pp. 437-447.

6. Chi-Jen Huang, Shyh-Jier Huang and Fu-Sheng Pai "Desi Dynamic Voltage Restorer With Disturbance-Filtering Enhancement" IEEE Transactionsronics,vol. 18,on pow no. 5, september 2003.

7. Bingsen Wang and Giri Venkataramanan, "Dynamic Voltage Restorer Utilizing a Matrix Converter and Flywheel Energy Storage"IEEE Transactions on industry applications, vol. 45, no. 1 , january/february 2009.

8. Bingsen Wang, Giri Venkataramanan and Mahesh Illindala, "Operation and control of a Dynamic Voltage Restorer Using transformer coupled H-bridge converters". IEEE Transactions on Power Electronics ( Volume: 21 , Issue: 4 , July2006 )

9. N.Karpagam,D.Devaraj,P.Subbaraj'Improved Fuzzy logic controller for SVC in power system Damping using global signals"springer,verlag,2010,volume 97,issue7.

10. Thakushi jimichi,member IEEE,hideaki,fujita member IEEE,hirofumi akagi fellow ,IEEE,"A dynamic voltage restorern equipped with a high frequency isolated DC-DC converter'.IEEE transactions on industry applications,volume -47,January,feb-2011

11. Carl Ngai-Man Ho, Henry Shu-Hung Chung,"implementation and performance of a fast dynamic control scheme for capacitor supported interline DVR'IEEE transactions on power electronics,volume 25,issue 8,1975-1988

\section{AUTHORS PROFILE}

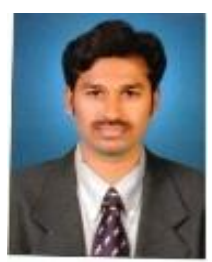

Nakka. Mahesh babu, .Assistant professor in EEE dept,Kodada Institute of Technology and Sciences for women,Kodad.He received his M.Tech from Dr.Paulraj Engineering college, Bhadrachalam, Khammam district. He received his B.Tech degree from Nagarjuna Institute of Technology and Sciences Miryalaguda. He also worked at Rajeev Gandhi international power plant at Haryana as site engineer for Electrostatic precipitator erection. He is working as Assistant professor in Electrical \&Electronics Engineering in Kodada Institute of Technology \&Sciences for women Kodad , Suryapet district. Telangana 508206.

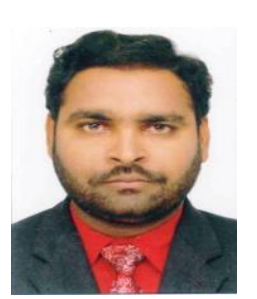

Dr.MD.AIJAZ, Assistant professor in EEE dept,Kodada Institute of Technology and sciences for women.He was born in KHAMMAM,Telangana,India.He received his B.Tech degree in Electrical and Electronics Engineering from Kakathiya University in 2007,Mtech degree in Power Electronics in2013 from the JNTUH,Hyderabad and received Ph.D from OPJS University,Churu,Rajasthan.His area of interest includes Electric machines and drives,power electronic converters,and renewable Energy Generation.He is now working as assistant professor in the Department of Electrical \&Electronics Engineering,Kdada Institute of Technology and Sciencesfor women,Kodad,suryapet District,andTelangana 508206. 